Revista Brasileira de Cartografia

ISSN 1808-0936 | https://doi.org/10.14393/revbrascartogr

Sociedade Brasileira de Cartografia, Geodésia, Fotogrametria e Sensoriamento Remoto

\title{
Evolução e Tendências nas Pesquisas em Administração Territorial e Cadastro
}

\section{Evolution and Trends in Research on Land Administration and Cadastre}

\author{
Andrea Flávia Tenório Carneiro ${ }^{1}$ e Camila Ribeiro Miranda ${ }^{2}$ \\ 1 Universidade Federal de Pernambuco - UFPE, Departamento de Engenharia Cartográfica, Recife-PE, Brasil. E-mail: \\ andrea.carneiro@ufpe.br \\ ORCID: http://orcid.org/0000-0002-2445-2330 \\ 2 Universidade Federal de Pernambuco - UFPE, Departamento de Engenharia Cartográfica, Recife-PE, Brasil. E-mail: \\ caamilarm@hotmail.com \\ ORCID: https://orcid.org/0000-0002-1200-7408
}

Resumo: Ao longo do tempo, as relações entre pessoas e terra, função primordial do cadastro, passaram a exigir novas demandas, fazendo com que os países estruturassem sistemas de administração territorial de cunho não somente técnico-organizacional, mas também voltados para atender a outras necessidades da sociedade, como a redução da desigualdade social e o monitoramento ambiental. A teoria da moderna administração territorial tem tido a sua importância reconhecida, do ponto de vista do desenvolvimento sócio-econômico-ambiental, porém a sua natureza científica ainda é discutida. Envolvendo aspectos sociais (história, cultura, economia, meio-ambiente) e de sistemas de informação e tecnologia, as pesquisas sobre os temas exigem a compreensão de conceitos que precisam ser consolidados e bem compreendidos. Nesse sentido, esse trabalho teve como objetivo expor e discutir os conceitos essenciais que precisam ser considerados para o desenvolvimento de projetos de pesquisa nessa área. Também apresenta os questionamentos de pesquisadores sobre o caráter científico da administração territorial, com base nos indicadores utilizados na determinação das áreas de conhecimento científico. Além disso, os resultados de pesquisas sobre metodologias aplicadas em projetos de pesquisa em cadastro e administração territorial, bem como as tendências identificadas nas pesquisas atuais são importantes para a elaboração de futuros projetos. Por fim, com base nesses estudos, foi realizado um levantamento das pesquisas realizadas no Brasil, para apresentação de um panorama geral do que tem sido objeto de produção científica nessa área. Espera-se, assim, que esse trabalho traga contribuições para pesquisas futuras na área da administração territorial.

Palavras-chave: Administração Territorial. Cadastro. Gestão Territorial. Cadastro brasileiro.

\begin{abstract}
Over time, the relationship between people and land, the primary function of the cadastre, began to require new demands, enabling countries to structure land administration systems not only technical-organizational, but also directed to meet other needs of society, such as reducing social inequality and environmental monitoring. The theory of modern land administration has had its importance recognized, from the point of view of socioeconomicenvironmental development, but its scientific nature is still discussed. Involving social aspects (history, culture, economy, environment) and information and technology systems, the studies on the themes require the understanding of concepts that need to be consolidated and well understood. In this sense, this work aimed to expose and discuss the essential concepts that need to be considered for the development of research projects in this area. It also presents researchers' questions about the scientific character of land administration, based on the indicators used in determining areas of scientific knowledge. In addition, the results of research on methodologies applied in cadastre and land administration research projects, as well as the trends identified in current research, are important for the development of future projects. Finally, based on these studies, a review of research carried out in Brazil was conducted to present an overview of what has been the object of scientific production in this area. It is hoped that this work will bring contributions to future research in the area of land administration.
\end{abstract}

Keywords: Land Administration. Cadastre. Land Management. Brazilian Cadastre.

\section{INTRODUÇÃO}

A administração territorial (land administration) é um termo relativamente recente, publicado pela primeira vez em UNECE (1996). O cadastro é considerado parte fundamental dos Sistemas de Informações 
Territoriais, que são constituídos essencialmente por cadastros e registros territoriais. O conceito da administração territorial tem por pilares fundamentais as quatro funções pertinentes à gestão territorial e ao desenvolvimento sustentável: posse, valor, uso e desenvolvimento da terra. Ao longo do tempo, as relações entre pessoas e terra, função primordial do cadastro, passaram a exigir novas demandas, fazendo com que os países estruturassem sistemas de administração territorial de cunho não somente técnico-organizacional, mas também voltados para atender a outras necessidades da sociedade, como a redução da desigualdade social e o monitoramento ambiental.

Com o desafio de identificar como os sistemas cadastrais vinham se estabelecendo nos diferentes países e, assim, contribuir com o avanço dos países em desenvolvimento e apoiar as políticas de sustentabilidade, a Federação Internacional de Geômetras (FIG) se destaca pelo apoio a pesquisas na área de administração territorial e cadastro, com publicações que servem de referência para pesquisadores e organismos internacionais. Desde o conhecido Statement on the Cadastre (FIG,1995) até o importante Cadastro 2014 (KAUFMANN; STEUDLER, 1998), a tecnologia ganha espaço e traz novas possibilidades de representação das feições geoespaciais. Em 2012, é publicada a ISO 19.152, um modelo de domínio de administração de terras (Land Administration Domain Model - LADM) que propõe a descrição dos sistemas cadastrais através de classes básicas que representam as relações entre pessoas e terras através dos seus direitos, restrições e responsabilidades.

Pesquisas mais recentes no âmbito internacional indicam uma mudança de paradigma nos conceitos mais tradicionais do cadastro, visando a flexibilização de exigências de precisão, para a estruturação de sistemas preliminares que possam auxiliar especialmente nos casos em que ainda não se conseguiu estruturar um sistema mínimo. Há uma urgência em possibilitar que os cadastros representem a dinâmica territorial de maneira clara, simples e que sejam flexíveis e adaptáveis a cada realidade. É o chamado cadastro Fit-ForPurpose, que busca garantir, principalmente para os países em desenvolvimento e carentes de sistemas cadastrais bem definidos, soluções tecnicamente aplicáveis e economicamente viáveis. Finalmente, a Agenda 2030 da ONU apresenta os 17 objetivos para o desenvolvimento sustentável, deixando claro que para atingir tais objetivos é fundamental que exista uma boa organização dos sistemas de administração territorial. Tais sistemas, portanto, são apresentados como instrumentos para a consecução dos objetivos do milênio. Ainda nesse sentido, em 2019 foi publicado pelo Comitê das Nações Unidas de Especialistas em Gerenciamento de Informações Territoriais Globais (UN-GGIM) um documento (UN-GGIM,2019) que orienta a estruturação de um sistema de informações territoriais eficiente, considerando as reformas legais, administrativas e de absorção de possibilidades tecnológicas para esse fim.

Com importância reconhecida do ponto de vista de desenvolvimento socio-econômico-ambiental, a teoria da moderna administração territorial ainda é discutida, no que diz respeito à sua natureza científica. Por envolver aspectos sociais (história, cultura, economia, meio-ambiente) e de sistemas de informação e tecnologia, envolve a compreensão de muitos conceitos que precisam ser consolidados e bem compreendidos.

Nesse sentido, esse trabalho teve como objetivo expor e discutir os conceitos essenciais que as autoras consideram que precisam ser compreendidos para o desenvolvimento de projetos de pesquisa nessa área. Também apresenta os questionamentos de pesquisadores sobre o caráter científico da administração territorial, com base nos indicadores utilizados para a determinação das áreas de conhecimento científico. Além disso, os resultados de pesquisas sobre metodologias aplicadas em projetos de pesquisa em cadastro e administração territorial, bem como as tendências identificadas nas pesquisas atuais, são importantes para a elaboração de futuros projetos. Por fim, com base nesses estudos, foi realizado um levantamento das pesquisas realizadas no Brasil, para apresentação de um panorama geral do que tem sido objeto de produção científica nessa área.

\section{UMA BASE CONCEITUAL PARA PESQUiSAS EM ADMINISTRAÇÃo TERRITORIAL E CADASTRO}

Uma análise da administração territorial como área do conhecimento exige um esforço no sentido de apresentar os conceitos mais amplamente utilizados, uma vez que os autores que se dedicaram a esse tipo de pesquisa apontam as bases conceituais como um dos fatores críticos na consolidação da área como ramo do conhecimento científico. 
As relações entre pessoas e terra variam de acordo com as realidades culturais, socioeconômicas e políticas de cada país. Variam também com o tempo, de acordo com as demandas pela terra e com a complexidade da sua ocupação, por isso é importante apresentar os elementos essenciais envolvidos na estruturação de sistemas que visam apoiar políticas de acesso à terra e de monitoramento do seu uso.

\subsection{Gestão territorial, administração territorial e cadastro}

A terra é um recurso finito e desde a antiguidade é reconhecida como patrimônio e sinônimo de poder e riqueza. A demanda crescente gerada pelo aumento da população urbana, e consequente aumento das necessidades por alimento e água, mostra que o seu uso e ocupação devem ser bem gerenciados, em prol da coletividade. Os princípios do desenvolvimento sustentável baseiam-se na busca pelo equilíbrio entre questões sociais, econômicas e ambientais relativos ao uso dos recursos do planeta.

Organismos internacionais tem se mobilizado no sentido de orientar e apoiar os países no sentido de desenvolver sistemas de informações territoriais atualizados e confiáveis, que sirvam de base para um gerenciamento eficiente do território, visando atingir os objetivos do desenvolvimento sustentável, pelo fim da pobreza e das desigualdades, e enfrentamento das consequências das mudanças climáticas.

A gestão territorial (land management) envolve a implementação de decisões políticas fundamentais sobre a natureza e a extensão dos investimentos na terra. Assim, envolve decisões operacionais rotineiras tomadas por administradores de terras, tais como agrimensores, avaliadores e oficiais de registro de imóveis. Do ponto de vista institucional, a gestão de terras inclui a formulação da política fundiária (land policy), a estrutura legal, a gestão de recursos, os arranjos da administração de terras e a gestão da informação territorial. Envolve tanto iniciativas governamentais quanto privadas. Já a governança territorial ou governança fundiária (land governance) diz respeito às políticas, processos e instituições responsáveis pelo gerenciamento da terra, incluindo propriedade e recursos naturais. Uma boa governança fundiária exige uma estrutura normativa e processos operacionais adequados, para implementar de maneira eficiente as políticas fundiárias, atendendo aos princípios do desenvolvimento sustentável. A administração territorial (land administration) é parte da infraestrutura que apoia uma boa gestão territorial (UNECE, 1996; UNECE, 2005; WILLIAMSON et.al, 2010).

O termo administração territorial foi estabelecido pela United Nations Economic Commission for Europe (UNECE) no documento Land Administration Guidelines (UNECE,1996), e se refere aos processos de determinar, registrar e disseminar informações sobre propriedade, valor e uso da terra e seus recursos associados. Tais processos, atualizados em UNECE (2005), incluem a determinação (adjudicação ou formalização) de direitos de propriedade e outros atributos da terra, relacionados ao seu valor e uso, o levantamento dos seus limites e sua descrição gráfica, além de documentação detalhada e a disponibilização de informações relevantes para os mercados imobiliários.

É importante considerar que essa definição foi estabelecida com base na experiência e necessidades dos países europeus, e nem sempre se aplica a casos de países em desenvolvimento, que costumam ter, além da propriedade, uma gama variada de regimes de posse territorial, como observa UN-GGIM (2015). Nesse caso, ainda segundo UN-GGIM (2015), a definição apresentada pela FAO (2002), parece mais adequada: é a maneira pela qual as regras de posse da terra são aplicadas e operacionalizadas. A administração territorial, formal ou informal, compreende então uma ampla variedade de sistemas e processos para administrar:

a) Direitos territoriais: a concessão de direitos territoriais; a delimitação dos limites das parcelas às quais os direitos são atribuídos; a transferência de uma parte para outra através de venda, arrendamento, empréstimo, presente ou herança; e o julgamento de dúvidas e disputas sobre direitos e limites de parcelas;

b) Regulamentação do uso do solo: planejamento e aplicação dos regulamentos e julgamento de conflitos referentes ao uso do solo;

c) Avaliação e tributação de terras: a arrecadação de receitas através de métodos de avaliação e tributação da terra e a resolução de disputas referentes à avaliação e tributação de terras. 
Os sistemas de administração territorial envolvem um conjunto de princípios que norteiam a coleta, o processamento, armazenamento e uso de dados sobre propriedade da terra, seu uso, qualidade, localização e mudança ao longo do tempo. Refere-se também aos bancos de dados estruturados para apoio à tomada de decisões com base nesses princípios (AUC-ECA-AfDB Consortium, 2010).

Surgindo como sistemas de apoio para a tributação imobiliária, os sistemas de administração territorial tiveram reconhecido, nas últimas décadas, um papel bem mais forte no sentido de fornecer a um país uma infraestrutura para a implementação de políticas e estratégias de administração de terras em apoio ao desenvolvimento sustentável, como afirmam documentos que trazem as justificativas e importância de implementação e aperfeiçoamento de tais sistemas, como a Declaração de Bathurst da FIG (FIG,1999), UNGGIM(2015) e UN-GGIM(2019). FIG (2009) ressalta que é crucial entender que um sistema de administração territorial nunca pode ser um fim em si mesmo; sua natureza é para servir à sociedade, seja qual for o aspecto atual dessa sociedade. O documento (UN-GGIM,2019) reforça ainda que o sistema de administração territorial relaciona pessoa e terra e informa como, o que, quem, quando e onde, referentes às principais funções da gestão territorial: a posse da terra, seu uso, valor e desenvolvimento. A Figura 1 mostra de uma maneira esquemática essa relação entre os sistemas de informação territorial e a gestão territorial, visando atender aos objetivos do desenvolvimento sustentável.

Figura 1 - Sistema de informações territoriais como base para uma gestão territorial eficiente e atendimento aos objetivos do desenvolvimento sustentável, segundo Williamson et al. (2010).

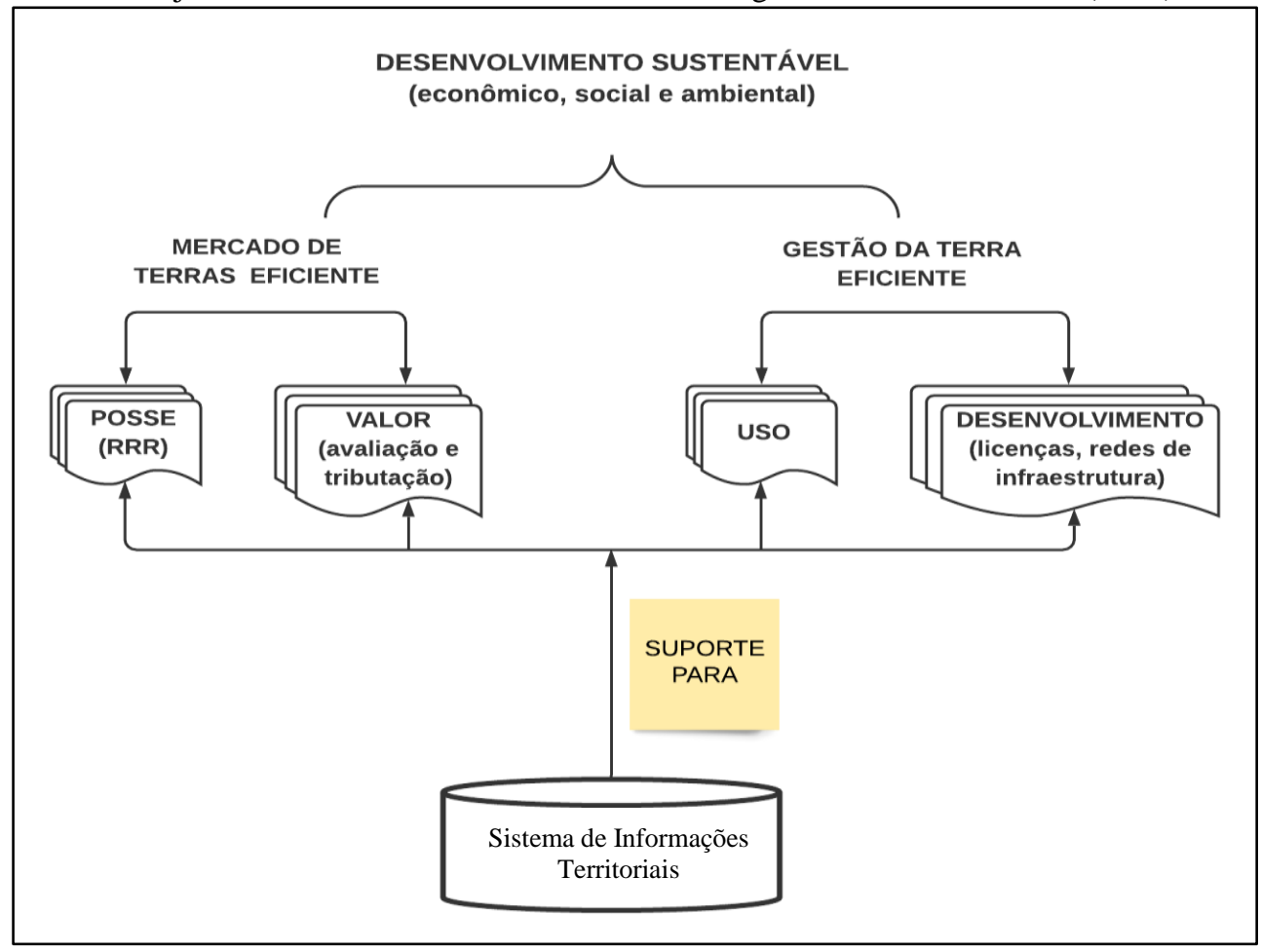

Fonte: Williamson et. al (2010).

Segundo FIG (2009), um sistema de administração territorial efetivo deve ser adequado à finalidade (fit-for-purpose), apropriado e adequado, interoperável e sustentável, flexível e inclusivo, e ser capaz de acelerar os esforços para documentar, registrar e reconhecer os relacionamentos entre pessoa e terra em todas as suas formas. Deve ajudar a garantir à humanidade um melhor acesso à terra e à segurança dos seus direitos, capaz de mitigar questões relacionadas à terra como causa de conflitos, e não deixar ninguém para trás, um princípio geral da Agenda 2030.

Para muitos países, isto é definitivamente uma ruptura com o passado, porque elementos considerados essenciais do sistema de administração territorial, como o cadastro e registro da terra, são considerados historicamente como um instrumento dos poderes coloniais ou de outra forma de governo para garantir seus próprios direitos à terra. Sistemas de administração territorial sustentáveis são, portanto, sistemas que servem bem à sociedade, ao fornecer conjuntos de produtos e serviços que agora são totalmente inclusivos, para 
atender à demanda atual e futura. Isto inclui os pobres que estão atualmente excluídos de participar em muitos países (FAO, 2002).

Assim como o entendimento a respeito da administração territorial evoluiu de acordo com as necessidades da sociedade, o mesmo ocorreu com o entendimento sobre o cadastro. Para Williamson et.al. (2010), o paradigma da gestão territorial faz de um cadastro nacional o motor do sistema de administração territorial, apoiando a capacidade de um país de alcançar os objetivos do desenvolvimento sustentável.

\subsection{A evolução do conceito de cadastro}

Enemark (2012) expressa de maneira enfática a importância do cadastro, quando afirma que o impacto de um cadastro bem estruturado dificilmente pode ser estimado, e que um sistema cadastral bem projetado atua como a espinha dorsal de uma sociedade. Por outro lado, o autor ressalta a dificuldade de se propor um conceito que se aplique a qualquer caso, uma vez que o cadastro pode ser projetado e implementado de várias maneiras, dependendo da origem, história e desenvolvimento cultural do país ou região. Basicamente, define o cadastro como um registro que identifica parcelas territoriais.

O conceito de cadastro tradicionalmente aceito diz que se trata de um sistema de informações territoriais atualizado, baseado em parcelas, contendo um registro de interesses sobre a terra (p.ex., direitos, restrições e responsabilidades). Geralmente inclui uma descrição geométrica de parcelas territoriais ligadas a outros registros que descrevem a natureza dos interesses, a propriedade ou o controle desses interesses, e frequentemente, o valor da parcela e suas benfeitorias. Pode ser estabelecido para fins fiscais, legais, apoiar o gerenciamento da terra e do uso do solo e apoiar o desenvolvimento sustentável e a proteção ambiental. Este é o conceito proposto em FIG (1995), que tem sido adotado por várias outras instituições e autores, como FIG (1999), UNECE (1996), UNECE (2005), Williamson et. al. (2010), dentre outros.

Silva e Stubkjær (2002) destacam a componente espacial do cadastro, concordando com Dale e McLaughlin (1989) e Larsson (1991), que definem o cadastro como uma descrição sistemática e oficial de parcelas territoriais, incluindo um identificador único para cada parcela. Além disso, o cadastro inclui dados descritivos contendo atributos das parcelas, e a representação dos limites de cada parcela em mapas de grande escala.

A ampliação do entendimento do cadastro, desde a sua função de instrumento para a cobrança de impostos, até o seu reconhecimento como parte fundamental de um sistema de administração que visa o desenvolvimento sustentável, está fortemente relacionado ao desenvolvimento das tecnologias de informação, que permitem a integração de sistemas de variadas fontes. Apesar dessas potencialidades, o desenvolvimento dos cadastros não ocorre satisfatoriamente em todos os países, porque a estruturação de tais sistemas não depende apenas do desenvolvimento tecnológico, e mesmo que assim fosse, nem todos tem acesso a estas tecnologias.

Para ilustrar essa evolução dos cadastros, a Figura 2 apresenta de uma forma muito simplificada os principais marcos de mudança, porém Williamson et. al. (2010) apresentam uma análise detalhada da relação dessa evolução do cadastro com aspectos históricos importantes. Um documento que merece destaque é o Cadastre 2014 (Kaufmann e Steudler, 1998), que trouxe pontos essenciais para o cadastro dos próximos vinte anos, e representou uma orientação importante nas reformas cadastrais que se seguiram. 
Figura 2 - O entendimento do cadastro ao longo do tempo, baseado em Williamson et al. (2010).

\begin{tabular}{|c|c|c|c|c|}
\hline até 1800's & até 1900's & a partir de 1960 s & século XX & 2014 \\
\hline $\begin{array}{l}\text { CADASIRO } \\
\text { FISCAL }\end{array}$ & $\begin{array}{l}\text { CADASTRO } \\
\text { LEGAL/ } \\
\text { MERCADODE } \\
\text { TERRAS }\end{array}$ & $\begin{array}{l}\text { CADASTRO PARA } \\
\text { FINSDE } \\
\text { PLANEJAMENTO }\end{array}$ & $\begin{array}{l}\text { CADASTRO } \\
\text { MULTIFINALITÁRIO }\end{array}$ & $\begin{array}{l}\text { CADASTRO FIT- } \\
\text { FOR-PURPOSE }\end{array}$ \\
\hline $\begin{array}{l}\text { Regime feudal, } \\
\text { primeiros cadastros } \\
\text { estabelecidos para } \\
\text { cobrança de tributos }\end{array}$ & $\begin{array}{l}\text { Cadastro } \\
\text { Napoleônico, } \\
\text { metodologia para o } \\
\text { Cadastro Moderno. }\end{array}$ & $\begin{array}{l}\text { Aceleração na } \\
\text { urbanização e } \\
\text { demanda por terras }\end{array}$ & $\begin{array}{l}\text { Tecnologias viabilizam } \\
\text { a integração de } \\
\text { bancos de dados }\end{array}$ & $\begin{array}{l}\text { finalidade, para que } \\
\text { possa agilizar a } \\
\text { regularização da posse } \\
\text { para todos, visando o } \\
\text { DESENVOLVMENTO } \\
\text { SUSTENTÁVEL }\end{array}$ \\
\hline
\end{tabular}

Fonte: As autoras (2020).

Para FIG (2014), o gargalo dos serviços de administração territoriais, para a maioria dos países que não conseguiram implementar tais sistemas, é o uso de técnicas de levantamento tradicionais e de alta precisão, consequentemente mais caras. UN-GGIM (2015) também reconhece que, em países em desenvolvimento, as formas convencionais de gerenciar e administrar a terra tem uma história de falhas para cumprir as suas funções, já que as soluções técnicas convencionais são muito caras, o que os torna financeiramente insustentáveis. Ao mesmo tempo, a necessidade de sistemas viáveis para gerenciar e administrar a terra é agora maior do que nunca, com novos desafios sendo acrescentados aos problemas que já existiam.

Propõe-se, assim, a implementação de um cadastro adequado à finalidade (fit-for-purpose), que deve ser flexível e focado nas necessidades dos cidadãos (como proporcionar segurança da posse e controle do uso do solo), ao invés de exigir soluções técnicas sofisticadas e levantamentos altamente precisos. Como características desses cadastros, FIG (2014) propõe que seja:

a) Flexível: nos métodos de captura de dados espaciais, de acordo com as condições de uso e ocupação do solo;

b) Inclusivo: no sentido de cobrir toda as formas de posse e todas as terras;

c) Participativo: com o apoio da comunidade na captura e uso de dados;

d) Acessível: para o uso institucional e para a sociedade em geral;

e) Confiável: em termos de informações que sejam confiáveis e atualizadas;

f) Viável: em relação à implementação do sistema no tempo planejado e dentro dos recursos disponíveis;

g) Atualizável: no que diz respeito ao aprimoramento e modernização em resposta às necessidades sociais e legais e às oportunidades econômicas.

\section{A ADMINISTRAÇÃO TERRITORIAL COMO ÁREA DE CONHECIMENTO CIENTÍFICO}

Como exposto no item anterior, a primeira vez que a administração territorial apareceu como uma área de conhecimento foi no documento da UNECE (UNECE, 1996), embora Williamson et. al. (2010) enfatizem que as raízes intelectuais da disciplina no gerenciamento das relações entre pessoa e terra e as ferramentas especializadas de levantamento são muito mais antigas. Métodos modernos de levantamento, como uma atividade que envolve coleta de informação territorial através de determinação precisa de limites e identificação da parcela, tem uma história de centenas de anos. Já Enemark (2004) lembra que a administração territorial é uma área intersetorial e multidisciplinar. Além disso, o relacionamento entre pessoa e terra varia dentro e entre países e regiões, e uma resposta adequada no sentido de formação de competências deve refletir essa característica básica.

Pesquisadores tem se dedicado a analisar a questão da administração territorial como área de conhecimento científico, e algumas abordagens serão apresentadas a seguir, com indicações de referências para os que quiserem se aprofundar nesse estudo. 


\subsection{Investigando a administração territorial como área do conhecimento}

Segundo Groenendijk et. al (2012), a administração territorial surgiu e ainda é fortemente baseada no cadastro e no registro de terras e disciplinas relacionadas. Os conceitos envolvidos no tema, no entanto, foram ampliados, como discutido na seção anterior, e as novas perspectivas da área de conhecimento administração territorial apontam em diferentes direções e distintas áreas. Em outras palavras, a administração territorial é caracterizada por múltiplas perspectivas e se baseia em diversas disciplinas, como: agrimensura, economia, direito, administração, engenharia, estatística, ciências sociais. Williamson et.al (2010) avaliam que a aplicação de metodologias científicas à teoria da administração territorial tem seu foco principal no projeto, construção e monitoramento de sistemas para atingir objetivos articulados. Isto, por sua vez, deu à administração territorial uma abordagem prática de encontrar soluções para absorver e aprender a partir de esforços fracassados, desde que as falhas fossem claramente aparentes. A tradição de tentar aperfeiçoar sistemas e métodos ajudou a produzir uma literatura na qual projetos de sistemas administrativos de escala grande são discutidos vigorosamente, e a avaliação dos projetos é discutida abertamente. A combinação de avaliação crítica e métodos científicos aplicados, ou a abordagem de engenharia, permanece aparente na teoria e prática de administração territorial moderna. A abordagem da administração territorial entra a seguir na fase de implementação, que está centrada em como construir cadastros multifinalitários, ao invés de porque eles deveriam ser construídos.

Groenendijk et.al (2012) observaram, porém, que o status da administração territorial como área de conhecimento defendido por Williamson et.al. (2010) não estava suficientemente claro, e que não há um entendimento único a esse respeito por parte dos principais pesquisadores, fato que não é incomum, uma vez que o termo administração territorial é relativamente novo em educação e pesquisa. A partir dessa constatação, realizaram uma pesquisa com o objetivo de responder a uma pergunta: qual a natureza da administração territorial como uma área de conhecimento? Para isso, utilizaram a metodologia aplicada por Scholl (2008), que investigou o e-governance como área de conhecimento. De acordo com Scholl (2008), as áreas de conhecimento são determinadas por comunidades acadêmicas que definem quais problemas devem ser estudados, desenvolvem certos conceitos centrais e teorias de organização, adotam certos métodos de pesquisa, proporcionam fóruns para compartilhar pesquisas e insights, e oferecem oportunidades de carreira para os acadêmicos. Uma área de conhecimento é um ramo particular de aprendizagem ou corpo de conhecimento cujos elementos definidores - isto é, fenômenos, suposições, epistemologia, conceitos, teorias e métodos - a distinguem de outras formações de conhecimento. Esse entendimento está de acordo com a definição utilizada pela CAPES (2020): “ Área do Conhecimento (Área Básica): conjunto de conhecimentos interrelacionados, coletivamente construído, reunido segundo a natureza do objeto de investigação com finalidades de ensino, pesquisa e aplicações práticas."

Para tentar qualificar e-governance como área de conhecimento, Scholl (2008) usou os seguintes indicadores e dimensões: 1) existência de uma definição formal; 2) uma base comum de conhecimentos; 3) um conjunto específico de problemas de pesquisa; 4) teorias convergentes; 5) procedimentos e métodos de pesquisa admitidos e 6) uma visão compartilhada da importância do domínio do estudo. Além desses indicadores, o autor incluiu: 7) elementos estruturais a nível universitário (departamentos, faculdades, universidades), 8) programas e estudantes de pós-graduação, 9) uma comunidade mundial de pesquisa, 10) associações acadêmicas e profissionais, 11) periódicos e conferências recorrentes, 12) autoidentificação do pesquisador com a disciplina, 13) líderes, ou seja, estudiosos de destaque e com visibilidade, 14) livros didáticos, 15) fidelidade à área do conhecimento, expressa por fatos e regras aceitas, 16) terminologia específica de temas da área, e 17) forte interação entre a área de conhecimento e seu campo de atuação.

Esse conjunto de indicadores foi utilizado por Groenendijk et.al (2012) para avaliar a natureza científica da administração territorial, através de pesquisa em publicações diversificadas, sites e outras fontes. Embora os autores não considerem os resultados como definitivos, merecendo ser aprofundados em algumas questões, concluem que a administração de terras representa uma disciplina ainda em formação, que pode ser considerada uma área emergente de estudo interdisciplinar, baseada principalmente nas áreas tradicionais de cadastro territorial (agrimensura/geodésia/cartografia) e registro de imóveis. Uma síntese dos resultados é apresentada no Quadro 1, podendo os detalhes da pesquisa serem consultados na publicação citada 
(GROENENDIJK et al.,2012).

Quadro 1 - Avaliação da natureza científica da administração territorial.

\begin{tabular}{|l|l|l|l|}
\hline CRITÉRIO & STATUS & CRITÉRIO & STATUS \\
\hline Uma definição formal & Sim & Associação científica e profissional & Sim \\
\hline Base comum de conhecimento & Não/parcial & Periódicos e conferências & Não/parcial \\
\hline Conjunto específico de problemas de pesquisa & Não/parcial & Pesquisadores identificados com a área & Parcial \\
\hline Teorias unificadoras & Não & Líderes/pesquisadores com visibilidade & Parcial \\
\hline Procedimentos e métodos de pesquisa & Não & Livros-texto & Sim \\
\hline Visão compartilhada & Não & $\begin{array}{l}\text { Fidelidade à área expressa por fatos e regras } \\
\text { aceitas }\end{array}$ & Parcial \\
\hline Elementos estruturais em nível universitário & Sim & Terminologia específica prática & Sim \\
\hline Programas e estudantes de pós-graduação & Sim & $\begin{array}{l}\text { Forte interação entre pesquisa e } \\
\text { profissional }\end{array}$ & \\
\hline $\begin{array}{l}\text { Uma comunidade de pesquisadores } \\
\text { distribuídos na comunidade internacional }\end{array}$ & Não & & \\
\hline
\end{tabular}

Fonte: Groenendijk et al. (2012).

Cagdas e Stubkjær (2009) também se dedicaram a analisar a administração territorial e o cadastro do ponto de vista científico. Os autores publicaram dois artigos, Cagdas e Stubkjær (2009) e Cagdas e Stubkjær (2011), nos quais foram analisadas metodologias utilizadas em 10 e 5 teses de doutorado, respectivamente. Em Cagdas e Stubkjær (2009), afirmam que apesar de contribuições importantes que tem sido desenvolvidas, ainda não é possível identificar uma teoria cadastral universal e coerente, até a época da publicação da pesquisa. Os autores salientam que teorias são construídas com conceitos, que tem que ser claros, precisos e de metas acordadas, e no estudo ainda fora observadas ambiguididades nas definições e usos dos conceitos.

Além da complexidade da proposição ou adoção de um conceito que seja universal no que tange ao tema cadastral, é preciso também destacar questões relacionadas à terminologia. Silva e Stubkjær (2002) apontam, por exemplo, a utilização dos termos cadastros e sistemas cadastrais, onde o termo sistemas cadastrais tem sido utilizado de uma maneira muito vaga, às vezes como sinônimo de cadastro. De acordo com Bogaerts (1999) apud Silva e Stubkjær (2002), um sistema cadastral é uma combinação de cadastro e registro de imóveis, e portanto não se pode utilizar os dois termos indistintamente. Esse entendimento é o mesmo de Enemark (2012), que afirma que faz sentido falar sobre sistemas cadastrais ou infraestruturas cadastrais, ao invés de cadastro, quando esses sistemas ou infraestruturas incluem a interação entre a identificação de parcelas territoriais, o registro dos direitos, a avaliação e a tributação e o controle do atual e possível uso futuro da terra. Para o autor, um sistema cadastral multifinalitário e maduro pode até mesmo ser considerado um sistema de administração territorial. O Quadro 2 apresenta uma síntese desses entendimentos.

Quadro 2 - Distinção de terminologias, baseado em Silva e Stubkjær (2002) e Enemark (2012).

\begin{tabular}{|c|c|c|}
\hline \multicolumn{1}{|c|}{ CADASTRO } & SISTEMA CADASTRAL & $\begin{array}{c}\text { CADASTRO MULTIFINALITÁRIO } \\
\text { (Sistema de administração territorial ?) }\end{array}$ \\
\hline$\bullet \quad \begin{array}{l}\text { descrição sistemática e } \\
\text { oficial de parcelas } \\
\text { dados descritivos (atributos) } \\
\text { representação dos limites de } \\
\text { cada parcela em mapas }\end{array}$ & CADASTRO & $\begin{array}{c}\text { CADASTRO } \\
+\end{array}$ \\
REGISTRO DE IMÓVEIS \\
+ \\
REGISTRO DE IMÓVEIS \\
CADASTROS TEMÁTICOS (uso do \\
solo, valor, dados ambientais, etc...)
\end{tabular}

Fonte: As autoras (2020).

Ainda com respeito à terminologia, muitos países utilizam o termo cadastro com o sentido tratado nessa pesquisa, sem necessidade de uma especificação: cadaster ou cadastre, catastro, kataster, catasto. Porém, em alguns países o termo cadastro tem outros significados, por isso utiliza-se cadastro predial (em Portugal e ex-colônias portuguesas), catastro territorial (em países latinoamericanos). No Brasil, onde o termo cadastro também tem um sentido mais amplo, várias terminologias tem sido utilizadas: cadastro imobiliário, cadastro municipal, cadastro fiscal, cadastro urbano ou cadastro rural, cadastro multifinalitário. A partir de 2009, com a divulgação da Portaria 511 (BRASIL, 2009), do Ministério das Cidades, observa-se um esforço no sentido de consolidar o termo cadastro territorial. 


\subsection{Os métodos utilizados em pesquisas sobre administração territorial e cadastro}

Cagdas e Stubkjær (2009) e Cagdas e Stubkjær (2011) analisaram as diferentes abordagens das pesquisas em administração territorial, e mais especificamente, cadastro territorial. Suas conclusões estão de acordo com a pesquisa de Groenendijk et.al (2012), no que diz respeito à necessidade de se consolidar terminologias e conceitos que possam contribuir para a construção de novas teorias dentro do domínio cadastral. Os autores classificaram as pesquisas em temas cadastrais em dois grandes grupos de abordagem:

a) no campo das ciências sociais: do ponto de vista antropológico, econômico, geográfico, histórico, legal, organizacional e político;

b) no campo da ciência da informação: que pode ser uma pesquisa comportamental, que visa identificar problemas organizacionais da relação homem-computador, ou uma pesquisa de projeto, que busca desenvolver mecanismos de tecnologia da informação para resolver tais problemas.

Em Cagdas e Stubkjær (2009), foram analisados os aspectos metodológicos e teóricos de dez teses de doutorado desenvolvidas no campo das ciências sociais. $\mathrm{O}$ artigo apresenta uma comparação detalhada dos métodos utilizados nas pesquisas, abrangendo técnicas de coleta e análise de dados, bem como os procedimentos que especificam como as pesquisas foram realizadas. Os autores destacam a ampla utilização dos métodos qualitativos, principalmente os estudos de casos.

Silva e Stubkjær (2002) e Cagdas e Stubkjær (2009) observam que os sistemas cadastrais e de administração territorial dependem de fatores sociais, econômicos e culturais que precisam ser compreendidos, e o método de estudo de casos permite identificar e descrever esses fatores e suas relações, por favorecer o entendimento dos sistemas existentes, antes de se propor um novo sistema ou solução.

Cagdas e Stubkjær (2011) analisaram os métodos utilizados em cinco teses de doutorado desenvolvidas no campo da ciência da informação. Nesse aspecto, os autores explicam que o paradigma da ciência comportamental procura desenvolver e verificar teorias para entender ou predizer o comportamento humano e organizacional, visando estabelecer um conjunto de conceitos que são utilizados na elaboração de leis, modelos e teorias. Por outro lado, o paradigma da pesquisa de projeto (design research) procura desenvolver e avaliar mecanismos para resolver os problemas organizacionais identificados.

O Quadro 3 apresenta uma síntese dos métodos de pesquisa utilizados nas pesquisas no campo das ciências sociais (CAGDAS; STUBKJÆR, 2009) e no campo das ciências da informação, do tipo pesquisa de projeto (CAGDAS; STUBKJÆR, 2011).

Quadro 3 - Metodologias utilizadas nas pesquisas na área do cadastro e administração territorial, baseado em Cagdas e Stubkjær (2009) e Cagdas e Stubkjær (2011).

\begin{tabular}{|c|c|c|}
\hline & Pesquisas no campo das ciências sociais & Pesquisas no campo das ciências da informação \\
\hline Abordagem & $\begin{array}{l}\text { Geografia; Fatores institucionais (história, estrutura } \\
\text { cultural e legal, incluindo normativas para situações } \\
\text { formais e informais, relações sociais da sociedades); } \\
\text { Atores ou partes interessadas (registro de imóveis, } \\
\text { cadastro e outras organizações governamentais, entre } \\
\text { outros); Procedimentos (adjudicação,transfe-rências } \\
\text { de imóveis, parcelamentos); Tecnologia (métodos de } \\
\text { levanta-mento e cartografia, sistemas de informações). }\end{array}$ & $\begin{array}{l}\text { Projeto e desenvolvimento de modelos para avaliar ou } \\
\text { melhorar os componentes dos sistemas cadastrais, } \\
\text { Sistemas de Informações Geográficas e Infraestru- } \\
\text { turas de Dados Espaciais. Alguns desses modelos } \\
\text { servem à comunidade empresarial, aplicando } \\
\text { inovações tecnológicas para melhorar a eficácia de } \\
\text { uma organização e seus serviços, outros servem à } \\
\text { comunidade acadêmica trazendo novas visões para } \\
\text { compreender melhor um fenômeno. }\end{array}$ \\
\hline Metodologia & $\begin{array}{l}\text { Revisão de literatura } \\
\text { Projeto de pesquisa com escolha do: } \\
\text { - método de pesquisa, incluindo o } \\
\text { - } \text { embasamento teórico } \\
\text { - método de coleta dos dados } \\
\text { - estudo de caso (ou população) } \\
\text { - desenvolvimento da pesquisa } \\
\text { - apresentação dos resultados (reclamações e } \\
\text { - validação) } \\
\text { discussão dos resultados e recomendações } \\
\text { para estudos adicionais }\end{array}$ & $\begin{array}{ll}\text { - } & \text { Identificação do problema e motivação } \\
\text { - } & \text { Definição dos objetivos para uma solução } \\
\text { - } & \text { Projeto e desenvolvimento (de construções } \\
& \text { conceituais, modelos, métodos, instâncias } \\
& \text { ou novas propriedades de recursos técnicos, } \\
& \text { sociais e/ou de informação) } \\
\text { - } & \text { Demonstração (experimento, simulação, } \\
\text { - } & \text { Estudo de caso, entre outros) } \\
\text { - } & \text { Avaliação } \\
\text { - } & \text { Comunicação }\end{array}$ \\
\hline
\end{tabular}

Fonte: As autoras (2020). 


\subsection{As tendências das pesquisas sobre administração territorial e cadastro}

Pimenta et al. (2017) explicam que as pesquisas bibliométricas são fundamentadas em métodos quantitativos e estatísticos, e evoluíram no século XXI graças à criação de programas computacionais destinados à técnicas bibliométricas, que tem atingido, gradativamente, maior popularidade, qualidade e quantidade de estudos publicados, auxiliando na compreensão do desempenho intelectual de pesquisadores. Pesquisas bibliométricas têm sido realizadas na área de informações geoespaciais, como SIG, Sensoriamento Remoto e Cadastro (LIU et al., 2016; ZHANG et al., 2017; POLAT, 2019; CHOI, 2020).

Choi (2020) realizou uma pesquisa bibliométrica no campo da pesquisa cadastral, envolvendo publicações de 1987 a 2019. O estudo combinou os métodos de pesquisa de análise semântica e rede de palavras-chave, como também determinou as características de cada grupo, analisou as redes do grupo e extraiu os índices de centralidade e densidade. Esta análise proporcionou evidência qualitativa e quantitativa do processo de evolução dos temas da pesquisa cadastral, e mostra claramente a expansão dos temas abordados, de acordo com a ampliação do entendimento de cadastro exposto anteriormente. A Figura 3 mostra a visualização das palavras-chave e suas interligações, referente ao período de 1987 a 2001 e a Figura 4 ilustra o período de 2008 a 2014, onde se pode observar as palavras ligadas a tecnologia no segundo período, que se diversificam ainda mais no período mais recente.

Figura 3 - Mapas das redes de palavras-chaves das publicações internacionais sobre cadastro, referente ao período de 1987 a 2001.

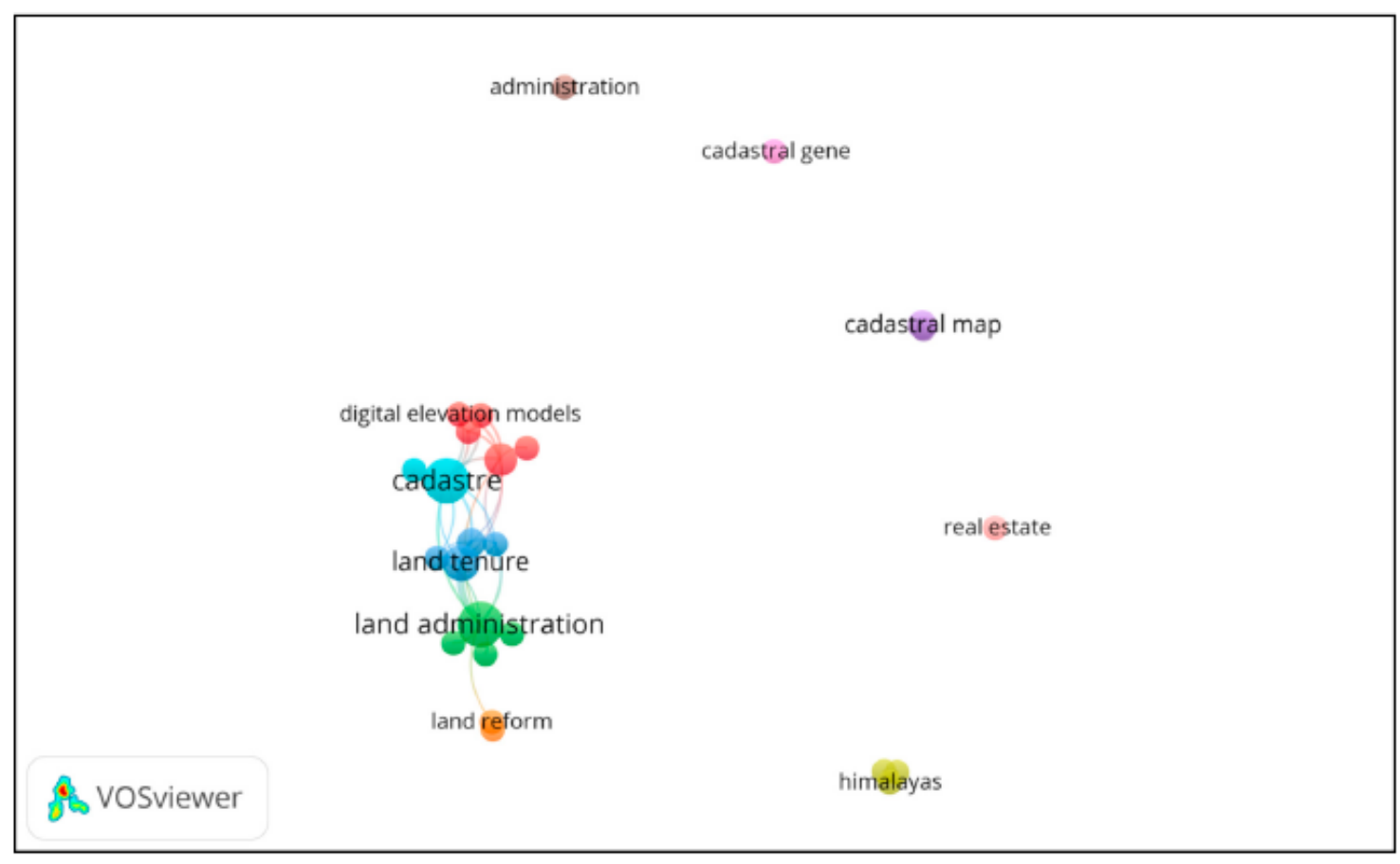

Fonte: Choi (2020). 
Figura 4 - Mapas das redes de palavras-chaves das publicações internacionais sobre cadastro, referente ao período de 2008 a 2014.

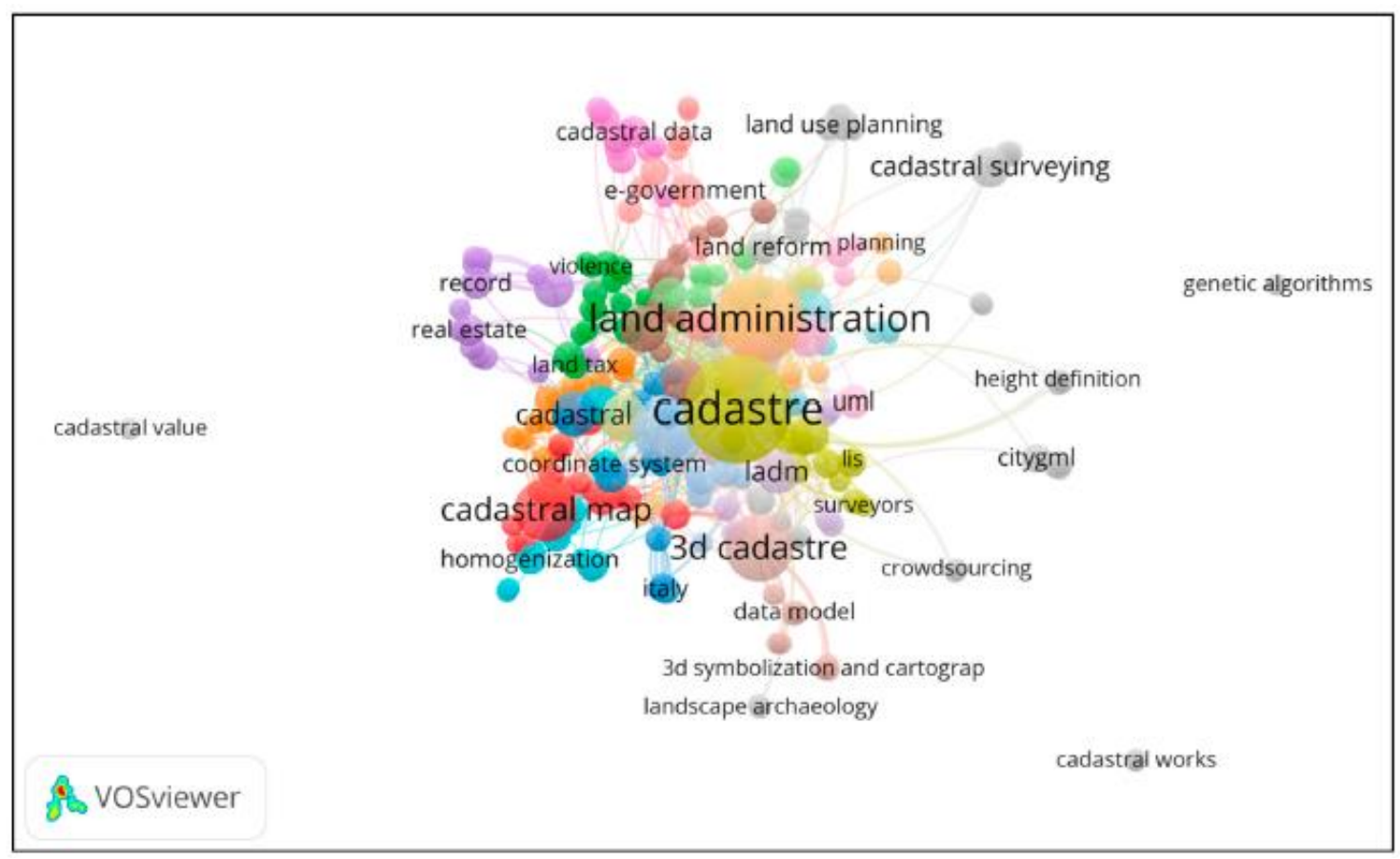

Fonte: Choi (2020).

Os resultados ilustram o avanço da aplicação de inovações tecnológicas nos cadastros, como ressaltado na combinação das palavras-chave relevantes, primordialmente relacionadas com a tecnologia da informação espacial e participação dos cidadãos na produção dos mapas cadastrais, através das Informações Geográficas Voluntárias $(V G I)$. A tendência confirmou que os dados abertos surgem como novas possibilidades na utilização de dados espaciais, e esses aspectos de inovação estão combinados com questões sociais. Choi (2020) salienta ainda que as pesquisas sobre padronização de dados espaciais cadastrais são um desafio, bem como a articulação com outras áreas de pesquisa. Cadastros em 3D e 4D proporcionam informações sobre os direitos acima e abaixo da superfície, e sua evolução com o tempo (STOTER et al., 2004; Van OOSTEROM, 2018; Van OOSTEROM et al., 2006; CARNEIRO; ERBA; ARRUDA, 2012).

A pesquisa conseguiu identificar também que o papel dos cadastros no fornecimento de bases legais para os direitos de propriedade da terra e ordenamento fundiário deve continuar. O que mudam são os métodos utilizados pelos cadastros, que também devem ser continuamente atualizados para uma política de gestão inteligente da terra. Portanto, os resultados reforçam a necessidade de uma compreensão sólida dos conceitos envolvidos no âmbito das pesquisas em temas cadastrais, para que se possa aplicar as inovações tecnológicas em benefício de um cadastro eficiente.

\section{UM PANORAMA DAS PESQUISAS EM ADMINISTRAÇÃO TERRITORIAL E CADASTRO NO BRASIL}

Após tratar dos conceitos e da natureza da administração territorial e do cadastro como área de conhecimento científico, foi realizada uma investigação sobre as pesquisas científicas no Brasil, no que concerne aos aspectos teóricos e práticos dos sistemas de administração territoriais e cadastros. Como resultado, obteve-se um inventário constituído por 132 produções científicas, entre artigos publicados no Boletim de Ciências Geodésicas - BCG, na Revista Brasileira de Cartografia - RBC e em revistas internacionais, além de teses e dissertações desenvolvidas na Universidade Federal de Pernambuco (UFPE), Universidade Federal de Santa Catarina (UFSC), Universidade Federal do Paraná (UFPR), Universidade do Estado de São Paulo - Campos Presidente Prudente (UNESP-PP), Universidade de São Paulo (USP) e Universidade Federal de São Carlos (UFSCar).

Para compreender a tendência dos principais temas abordados, foi realizada uma análise semântica das 
palavras-chave utilizadas nas publicações e sintetizadas em uma nuvem de palavras, que possibilitou representar a frequência com que os termos apareceram nas produções ao longo dos anos. Uma nuvem de palavras, assim como histogramas e gráficos, funciona como uma ferramenta que hierarquiza as palavras de acordo com a sua ocorrência e relevância, porém com uma linguagem visual e direta, onde o tamanho da palavra na nuvem é diretamente proporcional à frequência. Foram identificadas 394 palavras-chave e o problema da terminologia mencionado no item 3.1 fica evidenciado, com mais de um termo correspondendo ao mesmo conceito. Assim, para garantir que a nuvem de palavras tivesse a apresentação mais clara e objetiva possível, foram escolhidas 51 palavras, entre as que apresentaram as frequências mais representativa do universo pesquisado, e que correspondessem a conceitos distintos. O resultado está representado na Figura 5.

Figura 5 - Nuvem de Palavras das palavras-chave mais significativas das pesquisas na área de administração territorial e cadastro.

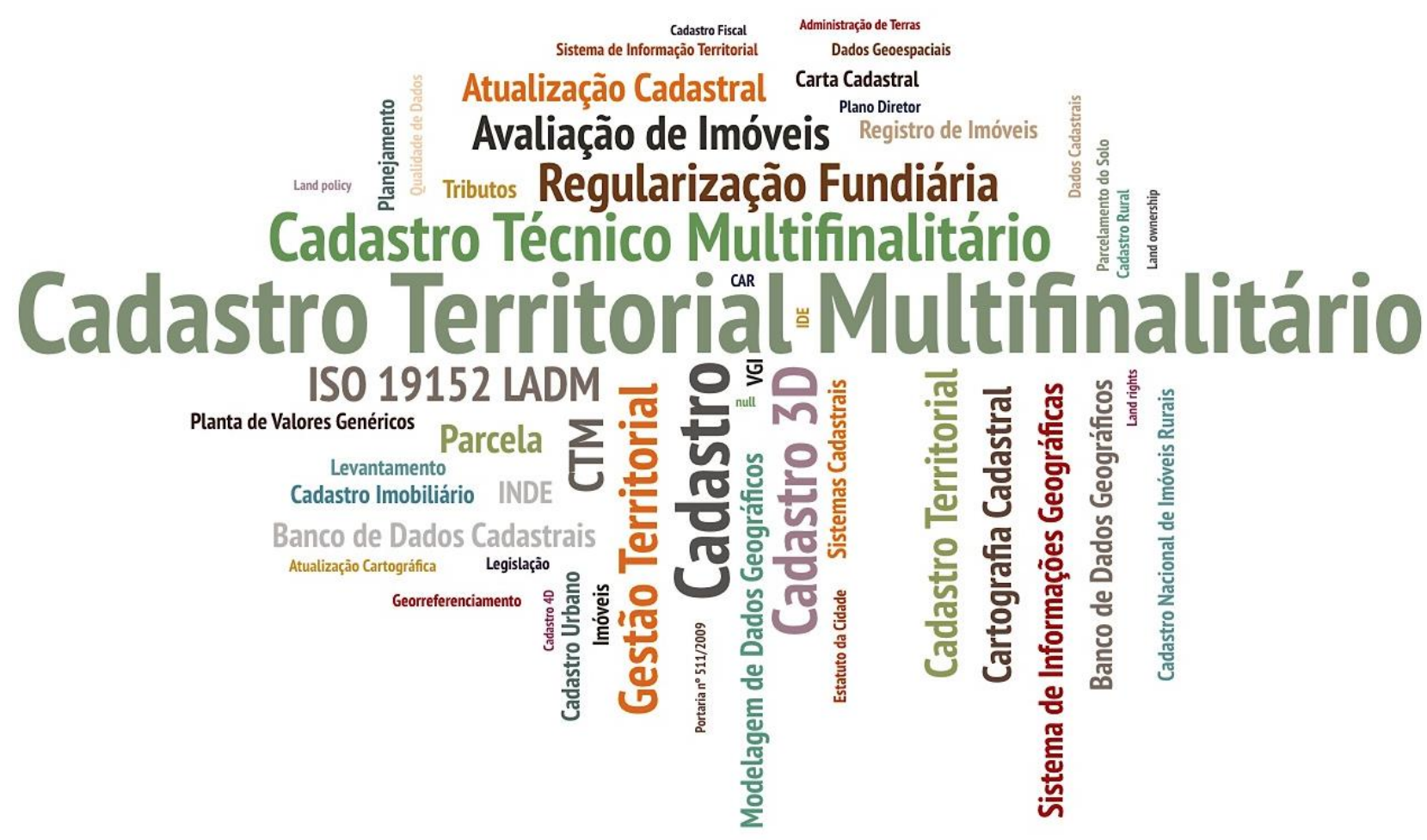

Fonte: As autoras (2020).

Assim como se observou nos estudos apresentados nos itens anteriores, o interesse acadêmico sobre o tema no Brasil está fortemente conectado com alterações na legislação territorial, seja pela necessidade de identificar e solucionar problemas, seja para fomentar discussões teóricas e conceituais, estabelecendo uma relação simbiótica. Assim, consequentemente, os adventos da Lei 10.267, responsável pela criação do Cadastro Nacional de Imóveis Rurais (CNIR), a Portaria 511/2009 do Ministério das Cidades, o Decreto 6.666/2008 e a ISO 19152:2012 - LADM (ISO, 2012; LEMMEN; OOSTEROM; BENNETT, 2015) ecoaram nas publicações de artigos científicos, dissertações e teses, que constituíram as pesquisas analisadas no presente trabalho. Com a publicação do Decreto 8764/2016, que instituiu o Sistema Nacional de Gestão de Informações Territoriais - SINTER, um sistema integrador de cadastros urbanos, rurais e registros de imóveis, espera-se que esse tema seja frequente nas pesquisas publicadas nos próximos anos.

\subsection{Evolução temporal dos temas abordados nas pesquisas}

Após identificado o comportamento geral das pesquisas através das principais palavras-chaves utilizadas, a evolução da ciência de administração territorial foi investigada de maneira mais específica durante os três intervalos: até 1999, de 2000 a 2009 e de 2010 até 2020. Para isso, foi necessário sumarizar as palavraschave e áreas temáticas em seis categorias, a partir da avaliação dos métodos, técnicas e fundamentação teórica 
das pesquisas, com o intuito de caracterizar e quantificar os estudos de acordo com a grande área de concentração, correlacionando com o comportamento evolutivo. As categorias criadas foram: Administração Territorial, Gestão Territorial, CTM (correspondendo a Cadastro Técnico Multifinalitário ou Cadastro Territorial Multifinalitário), Cadastro Urbano, Cadastro Rural e Cadastro 3D.

No período até 1999, foram identificadas dez (10) pesquisas, sendo pioneira a dissertação desenvolvida em 1979 pelo Prof. Tarcísio Ferreira da Silva, que propôs um modelo de cadastro metropolitano. Em 1991, foi criado no Programa de Pós-graduação em engenharia civil da UFSC, a área de concentração em Cadastro Técnico Multifinalitário e em 1994 foi realizado pelo mesmo grupo de pesquisadores o I Congresso de Cadastro Técnico Multifinalitário e Gestão Territorial - COBRAC. Embora esse trabalho tenha utilizado como base de dados apenas publicações em periódicos e teses e dissertações, é importante salientar a importância do COBRAC para a disseminação de trabalhos técnico-científicos na área

No período de 2000 a 2009, algumas ações levaram ao aperfeiçoamento do sistema de administração territorial e dos cadastros no Brasil. O cadastro rural prosperou com a Lei 10.267/2001, considerada um marco para a gestão territorial do país de forma geral, mesmo que aplicável somente para os imóveis rurais. Já no contexto urbano, a Portaria 511/2009 propôs diretrizes para a implementação do Cadastro Territorial Multifinalitário nos municípios brasileiros. Uma contribuição importante dessa normativa foi a proposta de adoção de um conceito de cadastro alinhado ao conceito da FIG. De acordo com BRASIL (2009), "O Cadastro Territorial Multifinalitário (CTM), quando adotado pelos Municípios brasileiros, será o inventário territorial oficial e sistemático do município e será embasado no levantamento dos limites de cada parcela, que recebe uma identificação numérica inequívoca." Em 2008, foi instituída a Infraestrutura Nacional de Dados Espaciais - INDE, através do Decreto 6.666/2008, com o objetivo de promover o ordenamento, armazenamento e disseminação dos dados geoespaciais. Como resultado desses avanços, tais normativas ajudaram de alguma forma a ampliar o interesse e a demanda pelo aperfeiçoamento dos cadastros, e motivaram o desenvolvimento de mais pesquisas sobre temas relacionados. Assim, do inventário de 132 pesquisas, 27\% foram publicadas nesse período de 2000 a 2009, distribuídas nos temas representados no gráfico da Figura 6. Este foi um período com discussões científicas mais consistentes, acompanhadas de normas e diretrizes.

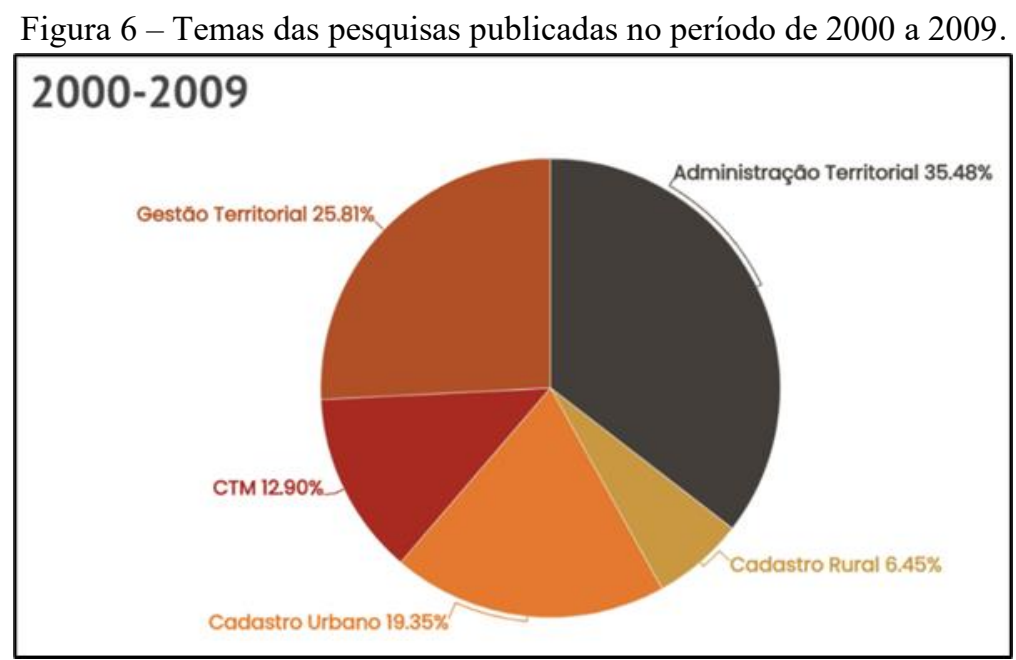

Fonte: As autoras (2020).

A maioria das pesquisas foram desenvolvidas na última década, entre 2010 e 2020, representando cerca de $70 \%$ do inventário. Observa-se que os conceitos e métodos relacionados à administração territorial foram se consolidando, e colaborando para o despertar da consciência cadastral no país. Quando a ISO 19152:2012 - LADM (ISO,2012) propôs a descrição dos cadastros a partir de pacotes, sub-pacotes e todas as relações envolvidas entres os agentes do cadastro territorial, assim como, os direitos, restrições e responsabilidades, alguns pesquisadores iniciaram a investigação da aplicabilidade do modelo, explorando suas potencialidades para os mais diversos cadastros brasileiros, como Paixão et al. (2015) e Purificação, Carneiro e Julião (2019). É importante destacar ainda a presença do tema Cadastro 3D, que não aparecia entre os mais frequentes no período anterior. Outro fato importante foi que o interesse em compreender a dinâmica 
territorial existente nos núcleos urbanos fez com que o cadastro urbano e sua aplicação à regularização fundiária fossem objeto de estudos e publicações. A Figura 7 ilustra os temas abordados nesse período.

Figura 7 - Temas das pesquisas publicadas no período de 2010 a 2020.

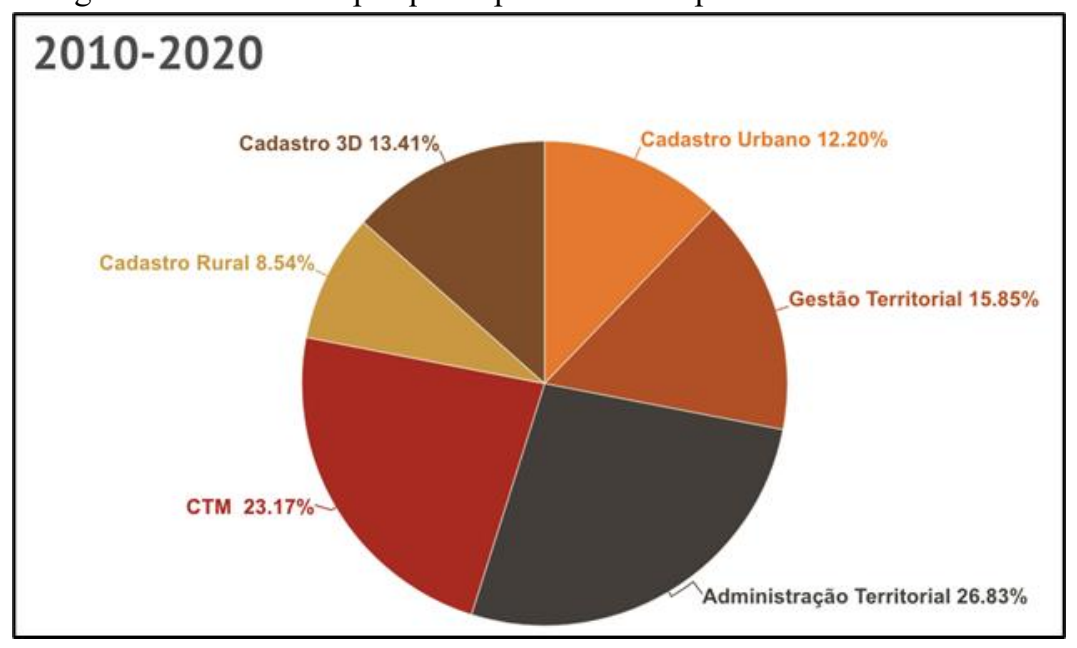

Fonte: As autoras (2020).

Com esse breve panorama sobre as pesquisas na área da administração territorial e cadastro no Brasil, observa-se que os pesquisadores têm buscado se alinhar ao desenvolvimento científico internacional, considerando as especificidades locais. $\mathrm{O}$ aumento das produções científicas é uma tendência que deve continuar, pela ampliação dos cursos de engenharia cartográfica e de agrimensura, e pelo crescente interesse por pesquisas multidisciplinares, como é o caso dessa área de pesquisa.

\section{CONSIDERAÇÕES FINAIS}

Esse estudo apresentou questões teóricas relevantes e atuais para as pesquisas sobre administração territorial e cadastro. O questionamento sobre a natureza da administração territorial como área de conhecimento científico e as consequentes indicações da necessidade da consolidação de conceitos e terminologias indicam o rumo que precisa ser seguido para o fortalecimento dessa emergente área do conhecimento. As análises sobre as tendências das pesquisas mais recentes mostram que uma teoria consistente ainda é fundamental para a proposição de modelos adequados às realidades de cada país, bem como para a exploração das tecnologias geoespaciais, de sistemas de informação e de manipulação de grandes bancos de dados no aperfeiçoamento dos cadastros.

Buscou ainda apresentar uma visão geral das pesquisas desenvolvidas no Brasil, concluindo que estas tem contribuído para a definição e aperfeiçoamento do arcabouço normativo atual, como também para a investigação da aplicação de novas tecnologias e desenvolvimento de modelos para o aprimoramento dos sistemas. Nesse sentido, é provável que nessa década que se inicia, os esforços sejam direcionados para analisar os cadastros territoriais como base para projetos de regularização fundiária, em atendimento à Lei 13.465/2017, e para contribuir para a estruturação do SINTER, pela sua importância na integração dos diversos cadastros brasileiros. Pesquisas em andamento também indicam um direcionamento para o estudo das possibilidades da utilização de informações voluntárias na estruturação de sistemas mais simplificados, que sirvam de informações preliminares para o atendimento às metas da Agenda 2030 da ONU.

Embora o presente trabalho não tenha se aprofundado nos conceitos e métodos que têm sido utilizados nas pesquisas brasileiras, a análise das palavras-chaves indicam as mesmas fragilidades conceituais e terminológicas apontadas nos estudos internacionais.

Espera-se que esse trabalho traga contribuições para pesquisas futuras na área da administração territorial, que tem sido considerada cada vez mais relevante para o planeta, como comprovam os estudos internacionais. Os documentos de organismos internacionais e as publicações da FIG tem servido de orientação segura para pesquisadores, mostrando temas relevantes e de interesse científico a serem explorados, 
por isso recomenda-se que os interessados procurem se manter atualizados nesse sentido.

\section{DESAFIOS E PERSPECTIVAS FUTURAS}

Um dos desafios identificados nas pesquisas é a necessidade de consolidação de um arcabouço teórico consistente para a formação de novos pesquisadores, bem como de profissionais técnicos em cadastro territorial. Nesse sentido, outros trabalhos como esse podem ser produzidos, aprofundando os temas que aparecem como relevantes no resultado dessa pesquisa.

Como perspectivas para desenvolvimentos futuros, recomenda-se investigar com mais profundidade as seguintes questões:

a) Quanto à multidisciplinaridade dos temas relacionados ao cadastro e gestão territorial, como intensificar a relação entre as questões tecnológicas e os aspectos das ciências sociais no Brasil?

b) Quanto aos aspectos técnicos, como considerar as possibilidades advindas de tecnologias acessíveis aos cidadãos, como informações voluntárias, e as necessidades de confiabilidade e qualidade dos dados cadastrais?

c) Quanto às contribuições para o estabelecimento de sistemas de administração territoriais alinhados com os objetivos do desenvolvimento do milênio, quais as estratégias para a viabilidade de tais sistemas, de forma que estes sejam aperfeiçoados continuamente?

\section{Agradecimentos}

As autoras agradecem à CAPES - Coordenação de Aperfeiçoamento de Pessoal de Nível Superior, pela bolsa de mestrado concedida.

\section{Contribuição dos Autores}

Conceitualização e supervisão sob responsabilidade de Andrea F.T. Carneiro. Investigação de Camila Ribeiro Miranda e Andrea F.T Carneiro. Metodologia e redação (minuta, revisão e edição) de Andrea F.T. Carneiro e Camila Ribeiro Miranda.

\section{Conflitos de Interesse}

As autoras declaram que não há conflito de interesse.

\section{Referências}

AUC-ECA-AfDB CONSORTIUM. Framework and Guidelines on Land Policy in Africa - Land Policy in Africa: A Framework to Strengthen Land Rights, Enhance Productivity and Secure Livelihoods. Addis Ababa: AUC-ECA-AfDB Consortium, 2010. Disponível em: https://www.uneca.org/sites/default/files/PublicationFiles/fg_on_land_policy_eng.pdf. Acesso em 31 jul. 2020.

BRASIL. Ministério das Cidades. Portaria n. 511 de 07 de dezembro de 2009. Diretrizes para a criação, instituição e atualização do Cadastro Territorial Multifinalitário (CTM) nos municípios brasileiros. Diário Oficial da República Federativa do Brasil, Poder Executivo, Brasília, DF, 08 dez. 2009. Seção 1, p.75.

ENEMARK, S. Building Land Information Policies, 2004. Proceedings of UN/FIG Special Forum on Building Land Information Policies in the Americas, Aguascalientes, Mexico, 26-27 out. 2004.

ENEMARK, S. From Cadastre to Land Governance. FIG WORKING WEEK, 2012, Rome. Proceedings of the FIG Working Week. Copenhagen: International Federation of Surveyors (FIG), 2012. 1-21. 
Disponível em: http://fig.net/resources/proceedings/figproceedings/fig2012/papers/ss06/SS06_ enemark_0000.pdf. Acesso em 03 ago. 2020.

CAGDAS, V.; STUBKJÆR, E.. Doctoral research on cadastral development. Land Use Policy, 26,4, 869-889, 2009. https://doi.org/10.1016/j.landusepol.2008.10.012. Disponível em: https://www.researchgate.net publication/222547643_Doctoral_research_on_cadastral_development. Acesso em: 17 jul. 2020.

CAGDAS, V.; STUBKJÆR, E. Design research for cadastral systems. Computers, Environment and Urban Systems, 35, 77-87, 2011. DOI. :10.1016/j.compenvurbsys.2010.07.003.

COORDENAÇÃO DE APERFEIÇOAMENTO DE PESSOAL DE NÍVEL SUPERIOR (CAPES). Tabelas de áreas de conhecimento/avaliação. Disponível em: https://www.capes.gov.br/acessoainformacao/informacoes-classificadas/91-conteudo-estatico/avaliacaocapes/6831-tabela-de-areas-de-conhecimentoavaliacao. Acesso em 03 ago. 2020.

CARNEIRO, A.F.T; ERBA, D.A.; ARRUDA, E.A.A. Cadastro Multifinalitário 3D: Conceitos e perspectivas de implantação no Brasil. Revista Brasileira de Cartografia, v. 64, n. 2, 11. 2012. Disponível em: http://www.seer.ufu.br/index.php/revistabrasileiracartografia/article/view/43791. Acesso em: 26 out. 2020.

CHOI, H.O. An Evolutionary Approach to Technology Innovation of Cadastre for Smart Land Management Policy. Land, 9, 50, 1-19, 2020. https://doi.org/10.3390/land9020050. Disponível em: https://www.mdpi. com /2073-445X/9/2/50. Acesso em 02 ago. 2020.

DALE, P.; MCLAUGHLIN, J. Land information management: an introduction with special reference to cadastral problems in Third World countries. Oxford: Oxford University Press, 1989.

FOOD AND AGRICULTURE ORGANIZATION (FAO). Land tenure and rural development. FAO Land

Tenure Studies. Rome: FAO, 2002. Disponível em: http://www.fao.org/3/y4307e/y4307e00.htm. Acesso em 01 ago. 2020.

FÉDÉRATION INTERNATIONALE DES GÉOMÈTRES (FIG). Fit-For-Purpose Land Administration. FIG publications n.60. Copenhagen: International Federation of Surveyors (FIG), 2014. Disponível em: https://www.fig.net/resources/publications/figpub/ pub60/Figpub60.pdf. Acesso em 01 ago. 2020.

FÉDÉRATION INTERNATIONALE DES GÉOMÈTRES (FIG). Land Governance in Support of The Millennium Development Goals. FIG publications n.45. Copenhagen: International Federation of Surveyors (FIG), 2009. Disponível em: https://www.fig.net/ resources/publications/ figpub/pub45/figpub45.pdf. Acesso em 28 jul. 2020.

FÉDÉRATION INTERNATIONALE DES GÉOMÈTRES (FIG). Statement on the Cadastre. FIG publications n.11. Copenhagen: International Federation of Surveyors (FIG), 1995. Disponível em: https://www.fig.net/resources/publications/figpub/pub11/figpub11.asp. Acesso em 26 jul. 2020.

FÉDÉRATION INTERNATIONALE DES GÉOMÈTRES (FIG). The Bathurst Declaration on Land Administration for Sustainable Development. Copenhagen: International Federation of Surveyors (FIG), 1999. Disponível em: https://www.fig.net/resources/ publications/figpub/pub21/figpub21.asp. Acesso em 28 jul. 2020.

GROENENDIJK, L. et. al. Land administration as an academic discipline: to be, or not to be. FIG WORKING WEEK, 2012, Rome. Proceedings of the FIG Working Week. Copenhagen: International Federation of Surveyors (FIG), 2012. Disponível em: https://www.oicrf.org/-/land-administration-as-an-academicdiscipline-to-be-or-not-to--1. Acesso em 25 jul. 2020.

KAUFMANN, J.; STEUDLER, D. Cadastre 2014 - A Vision for a Future Cadastral System. Rüdlingen: International Federation of Surveyors (FIG), 1998. Disponível em: https://www.fig.net/resources/publications/ figpub/cadastre2014/translation/c2014-english.pdf. Acesso em 29 jul. 2020.

LARSSON, G. Land registration and cadastral systems. Essex: Longman Scientific and Technical, 1991.

LEMMEN, C.; Van OOSTEROM, P.; BENNETT, R. The Land Administration Domain Model. Land Use Policy, v.49, p535-545, $2015 . \quad$ Disponível em: 
https://www.sciencedirect.com/science/article/pii/S0264837715000174. Acesso em: 26 out. 2020.

LIU, F. LIN, A.; WANG, H.; PENG, Y.; HONG, S. Global Research Trends fo Geographical Information System from 1961 to 2010: A bibliometric analysis. Scientometrics, 106, 751-768, 2016.

PAIXÃO, S. K.; HESPANHA, J.; GHAWANA, T.; CARNEIRO, A. F. T; ZEVENBERGEN, J.; FREDERICO, L.N. Modeling indigenous tribes' land rights with ISO 19152 LADM: A case from Brazil. Land Use Policy, $\quad$ v.49, 587-597, 2015. Disponível em: https://www.sciencedirect.com/science/article/abs/pii/S0264837714002725. Acesso em: 26 out. 2020.

PIMENTA, A. A.; PORTELA, A. R. M. R.; OLIVEIRA, C. B.; RIBEIRO, R. M. A Bibliometria nas Pesquisas Acadêmicas. SCIENTIA: Revista de Ensino, Pesquisa e Extensão, v. 4, n. 7, p. 1-13, 2017. Disponível em: https://flucianofeijao.com.br/novo/wp-content/uploads/2017/12/EDUCAR_PARA_A_CIDADANIA FINANCEIRA.pdf. Acesso em 02 ago. 2020.

POLAT, Z. A. Evolution and future trends in global research on cadastre: a bibliometric analysis. Geojournal, 84, 1121-1134, 2019.

PURIFICAÇÃO, N.R.S.; CARNEIRO, A.F.T.; JULIÃO, R.P. A proposal for modeling and implementing an integrated system for brazilian cadastres according to iso 19152:2012 Land Administration Domain Model. Bol. Ciênc. Geod., Curitiba , v. 25, n. 4, 2019; DOI.: 10.1590/s1982-21702019000400026.

SCHOLL, H. J. Discipline or Interdisciplinary Study Domain? Challenges and Promises in Electronic Government Research. In: CHEN H. et al. (eds) Digital Government. Integrated Series In Information Systems, v. 17. Boston: Springer, 2008. p.22-41. DOI.: 10.1007/978-0-387-71611-4_2.

SILVA, M.A.; STUBKJÆR, E. A review of methodologies used in research on cadastral development. Computers, Environment and Urban Systems, 26, 403-423, 2002. DOI.: 10.1016/S01989715(02)00011-X.

STOTER, J. E.; van OOSTEROM, P. J. M.; PLOEGER, H. D.; AALDERS, H. J. G. L. Conceptual 3D Cadastral Model applied in several countries. In: Proceedings of the FIG Working Week. Atenas, 2004. Disponível em: <http://www.gdmc.nl/publications/2004/3D_cadastral_model.pdf>. Acesso em 26 out. 2020.

UNITED NATIONS ECONOMIC COMMISSION FOR EUROPE (UNECE). Land Administration in the UNECE Region: Development, Trends and Main Principles. New York and Geneva: United Nations Publications, 2005. Disponível em: http://www.unece.org/fileadmin/ DAM/hlm/documents/Publications/landadmin.devt.trends.e.pdf. Acesso em 28 jul. 2020.

UNITED NATIONS ECONOMIC COMMISSION FOR EUROPE (UNECE). Land Administration Guidelines with Special Reference to Countries in Transition. New York and Geneva: United Nations Publications, 1996. Disponível em: http://www.unece.org/fileadmin/DAM/ hlm/documents/Publications/land.administration.guidelines.e.pdf. Acesso em 28 jul. 2020.

UNITED NATIONS COMMITTEE OF EXPERTS ON GLOBAL GEOSPATIAL INFORMATION MANAGEMENT (UN-GGIM). The Application of Geospatial Information - Land Administration and Management. United Nations Committee of Experts on Global Geospatial Information Management (UN-GGIM), 2015. Disponível em: http://ggim.un.org/meetings/GGIM-committee/documents/GGIM5/ and\%20admin\%20and\% 20mngnt\%20background\%20paper\%203.2\%20final.pdf. Acesso em: 27 ago. 2020.

UNITED NATIONS COMMITTEE OF EXPERTS ON GLOBAL GEOSPATIAL INFORMATION MANAGEMENT (UN-GGIM). Framework for Effective Land Administration: A reference for developing, reforming, renewing, strengthening or modernizing land administration and management systems. United Nations Committee of Experts on Global Geospatial Information Management (UN-GGIM), 2019. Disponível em: https://ggim.un.org/meetings/GGIM-committee/9thSession/documents/ E_C.20_2020_10_Add_1_LAM_background.pdf. Acesso em 01 ago. 2020

Van OOSTEROM, P (ed.). Best practices 3D Cadastres - Extended Version. FIG Publication, 2018. Disponível em: http://www.gdmc.nl/3DCadastres/FIG_3DCad.pdf. Acesso em: 26 out. 2020. 
Van OOSTEROM, P., PlOEGER, H., STOTER, J., THOMPSON, R., LEMMEN, C. Aspects of a 4D Cadastre: A First Exploration. In: Proceedings of the XXIII FIG Congress. Munique, 2006. Disponível em: http://www.gdmc.nl/publications/2006/Aspects_of_4D_Cadastre.pdf. Acesso em: 26 ago. 2020.

WILLIAMSON, I. et. al. Land administration for sustainable development. Redlands: ESRI Press, 2010.

ZHANG, H. et. al. Bibliometric analysis of global remote sensing research during 2010-2015. (Open Access). ISPRS International Journal of Geo-Information, , 6, 332, 1-19, 2017. DOI.:10.3390/ijgi6110332.

\section{Biografias das autoras}

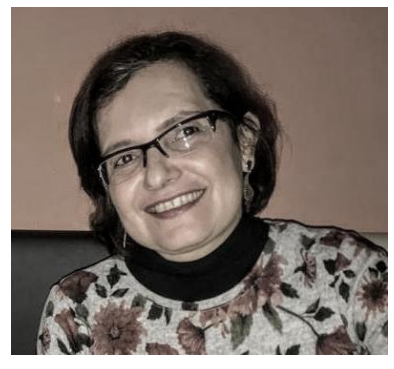

Andrea Flávia Tenório Carneiro, Arcoverde-PE-Brasil, 1966. Engenheira Cartógrafa pela Universidade Federal de Pernambuco - UFPE em 1989. Mestre em ciências geodésicas pela Universidade Federal do Paraná - UFPR em 1993 e doutora em engenharia de produção pela Universidade Federal de Santa Catarina UFSC em 2000. Realizou estágio pós-doutoral na Universidade Nova de Lisboa UNL em 2018. Docente do Departamento de Engenharia Cartográfica da UFPE desde 1994, em Recife-PE. Atua no ensino e pesquisa nas áreas de cadastro e gestão territorial nos cursos de engenharia cartográfica e de agrimensura e de pósgraduação em ciências geodésicas e tecnologias da geoinformação.

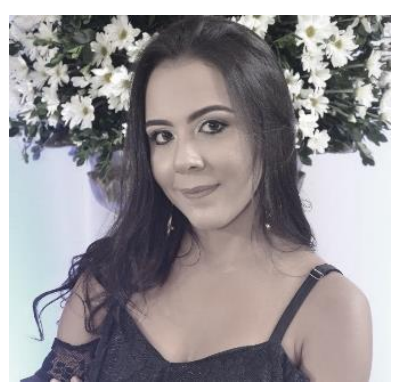

Camila Ribeiro Miranda, Salvador-BA-Brasil, 1994. Engenheira Agrimensora pela Universidade Federal de Alagoas - UFAL em 2018. Realizou graduação sanduíche na University of Colorado Boulder em 2014. Mestranda em Ciências Geodésicas e Tecnologias da Geoinformação pela Universidade Federal de Pernambuco. Possui experiência na área de geociências, com ênfase em cadastro territorial, geoprocessamento, mapeamento de áreas de riscos e planejamento territorial urbano.

Esta obra está licenciada com uma Licença Creative Commons Atribuição 4.0 Internacional - CC BY. Esta licença permite que outros distribuam, remixem, adaptem e criem a partir do seu trabalho, mesmo para fins comerciais, desde que lhe atribuam o devido crédito pela criação original. 